some effective way the time of the men who are standing by, and the report recommends that the fullest use should be made of the skilled men in the Service by the setting up of workshops for the repair of motor-vehicles and also for the repair of uniforms.

While the report recommends that the practice of allowing men on duty to do some industrial work at their stations should be encouraged and expanded at once to the utmost extent possible without interfering with their routine duties and training, the attitude of the Select Committee on this question is similar to that of Mr. Morrison as indicated in his speech on July 30 ; neither seems to realize the very serious problem of man-power which is involved and is likely to increase in gravity. The Committee's objection to the 24-24 hour system that such a practice may not be good for the Service, as a man may very easily become more interested in his civilian job, can scarcely be taken seriously in the present situation. If a uniform system of hours is to be adopted for the whole country, as the Committee recommends, the effects of the 24-24 hours system with the men directed to eight-hour factory shifts on their days off during lulls, as is being attempted in the north-west of England, should be examined.

Somewhat surprisingly, the other aspect of this question of hours and of the importance of alternative occupation is rather overlooked by the Committee. The report shows little appreciation of the real dangers to efficiency which arise from keeping men too long confined to their stations, and insufficient attention is given to welfare work in the National Fire Service. The Committee in fact scarcely appears to realize that the troubles of the National Fire Service spring chiefly from long periods of inaction and the failure to divert or occupy its members ; indeed it suggests that welfare should be primarily the responsibility of the various commanding officers, assisted by the establishment officer, and it is recommended that welfare officers should not be specially appointed. Probably officers who can find leisure occupation for the men and watch over their conditions of living, eating and sleeping are the greatest need of the National Fire Service to-day. Moreover, although a wide view of welfare not limited to sporting activities is taken, nothing is said on the question of educational service. That has still to receive o:ficial encouragement ; indeed in London, where it was commenced by the men, it was for long hindered rather than helped, and other regions have nothing of the kind. Nevertheless, the need of the Fire Service for educational service is just as great as that of the Army, where its value has long been recognized.

There are few ways in which the local authorities could better display their interest in the fire service now that it has been nationalized. The health and cultural welfare of this body of men, their own citizens, though now serving in a national force, gives a great opportunity. They could do much to support educational schemes, even if they cannot assist in their initiation, and to demand and maintain good living conditions. Whatever advantages there may have been in a local service with its fuller knowledge of local conditions could at least be utilized in welfare work, with benefit in efficiency and morale.

To bring to concert pitch, adequately but not overstaffed, such a force as the National Fire Service, and to maintain that efficiency over prolonged periods of inactivity, demand inspired leadership alive to the human issues as well as to the technical problems involved.

\section{CONTACT RESISTANCE}

$T$ $\mathrm{HE}$ effects of contact resistance on temperature rise in switches are examined by $\mathbf{R}$. W. $J$. Cockram in the Electrical Review of August 21. A factor complicating the control of electric circuits is the contact resistance set up between two mating surfaces of metal which at times have to be separated in order to break continuity of supply. The two main methods of decreasing contact resistance-excluding the use of special contact tips-are to increase the contact area and to increase the contact pressure. Contact pressure can be increased only to a certain limit, beyond which it results in a welding-in of contacts. Large contact surfaces are uneconomical; they are, in fact, made as small as possible consistent with a contact pressure low enough to preclude welding-in.

Knife type contacts depend mainly on large contact-surface area rather than high mating surface pressures to maintain low resistance values. Unless enclosed they are operated only under no-load conditions, and should not be worked in excess of 500 amp./sq. in. Point butt-type contacts mainly find application on instrument-control switches, controlcircuit contacts or interlocks on contactor gear. Rarely rated above 5 amp. at 440 volts, their contacts are usually of silver and take the form of portions of spheres, two breaks in series being employed. A slight 'wiping' action takes place which assists oxide removal. Line butt-type contacts are also chiefly associated with contactor apparatus. In these, heavy pressures are applied, generally to the main poles of contactors up to $150 \mathrm{amp}$. with spring pressures of 8-10 lb./sq. in. Replaceable contact tips are used, and a degree of wiping is provided. Surface type contacts call for complete mating of the contact surfaces; each moving contact is divided into four segments, each segment being acted upon by two springs. 'Taper-butt surfaces are employed for the control of heavy currents, as in circuit breakers and similar equipment.

In all the forms of contacts cited, pressure is applied to the mating surfaces. Some small degree of spot welding may be permitted while the wiping action is sufficient to break it; it is, however, best prevented. Burning and pitting was at one time considered to take place during the breaking of circuits but it is now mainly attributed to imperfect mating over long periods in the engaged position, the resulting oxidation causing further heating. Silver contacts are accordingly used, giving a greater working life since silver oxide is a comparatively good conductor.

\section{MAGNETIC FLUXMETER}

$M$

EASUREMENT of magnetic field strength due to current in a coil is usually made by changing the current and observing the voltage induced in a search coil or in the coil itself. This voltage is proportional to the rate at which the magnetic flux varies and it fluctuates in magnitude and direction, if the field pulsates or alternates. For rapid flux alternations a galvanometer will show no deflexion, but a steady reading can be obtained if the galvanometer connexions are reversed as the induced current reverses. The deflexion is then a measure of the magnetic field under observation. A practical application of this method is the measurement of voltage 